\title{
International Journal of Applied Research in Mechanical
}

\section{Engineering}

April 2012

\section{SIMULATION OF VEHICULAR FRONTAL CRASH-TEST}

\author{
TEJASAGAR AMBATI \\ Dept. Mechanical Engineering, Godavari Institute of Engg \& Tech., Rajahmundry, India, \\ tejasagar@gmail.com \\ K.V.N.S. SRIKANTH \\ CAD-CAM, Dept. of Mechanical Engineering, Godavari Institute of Engg. \& Tech., Rajahmundry, India, \\ kvnssrikanth@gmail.com \\ P. VEERARAJU \\ Dept. Mechanical Engineering, Godavari Institute of Engg \& Tech., Rajahmundry, India, \\ veeraraju1951@gmail.com
}

Follow this and additional works at: https://www.interscience.in/ijarme

Part of the Aerospace Engineering Commons, and the Mechanical Engineering Commons

\section{Recommended Citation 4, Article 7. \\ DOI: 10.47893/IJARME.2012.1047 \\ Available at: https://www.interscience.in/ijarme/vol1/iss4/7}

AMBATI, TEJASAGAR; SRIKANTH, K.V.N.S.; and VEERARAJU, P. (2012) "SIMULATION OF VEHICULAR FRONTAL CRASH-TEST," International Journal of Applied Research in Mechanical Engineering: Vol. 1: Iss.

This Article is brought to you for free and open access by the Interscience Journals at Interscience Research Network. It has been accepted for inclusion in International Journal of Applied Research in Mechanical Engineering by an authorized editor of Interscience Research Network. For more information, please contact sritampatnaik@gmail.com. 


\title{
SIMULATION OF VEHICULAR FRONTAL CRASH-TEST
}

\author{
TEJASAGAR AMBATI, K.V.N.S. SRIKANTH \& P. VEERARAJU
}

Dept. Mechanical Engineering, Godavari Institute of Engg \& Tech., Rajahmundry, India

E-mail : tejasagar@gmail.com, kvnssrikanth@gmail.com, veeraraju1951@gmail.com

\begin{abstract}
This paper "SIMULATION OF FRONTAL CRASH-TEST" The simulation of vehicle crashes by using computer softwares has become an indispensible tool for shortening automobile development time and lowering costs. It also has huge impact on the crashworthiness of an automobile.

This work reports on the simulated crash test of an automobile. The objective of this work is to simulate a frontal impact crash of an automobile and validate the results. The aim is also to alter some of the materials of the components with a view to reduce the forces experienced during the crash. Computer models were used to test the crash characteristics of the vehicle in the crash. The model used here was that of a Chevrolet C1500 pick-up truck.
\end{abstract}

The software used for the simulation is LS-DYNA. It is widely used by the automotive industry to analyze vehicle designs. It accurately predicts a car's behavior in a collision.

The results obtained by the simulation were then validated by comparing it with the test results of the same test performed by the NCAC (National Crash Analysis Center).

Keywords - CRASH TESTS; FEA; LS-DYNA; Proposing alternative materials;

\section{INTRODUCTION}

In modern engineering analysis it is rare to find a project that does not require some type of simulation for analyzing the behavior of the model under certain specified conditions. The advantages of simulation are numerous and important. A new design concept may be modeled to determine its real world behavior under various load environments, and may therefore be refined prior to the creation of drawings, when few dollars have been committed and changes are inexpensive. Once a detailed CAD model has been developed, simulations can analyze the design in detail, saving time and money by reducing the number of prototypes required. An existing product which is experiencing a field problem, or is simply being improved, can be analyzed to speed an engineering change and reduce its cost.

The finite element method is comprised of three major phases: (1) pre-processing, in which the analyst develops a finite element mesh to divide the subject geometry into sub-domains for mathematical analysis, and applies material properties and boundary conditions, (2)solution, during which the program derives the governing matrix equations from the model and solves for the primary quantities, and (3) post-processing, in which the analyst checks the validity of the solution, examines the values of primary quantities (such as displacements and stresses), and derives and examines additional quantities (such as specialized stresses and error indicators).

\section{Crash- Test}

A crash-test is a form of destructive testing usually performed in order to ensure safe design standards in crashworthiness and crash compatibility for automobiles or related components. To test the cars safety performance under various conditions and during varied types of crashes, vehicle manufacturers crash test their cars from different angles, different sides and with different objects, including other vehicles.

The most common types of crash tests are listed below.

$>$ Front impact test

$>$ Front offset crash test

$>$ Side impact test

$>$ Roll over test

\section{Method Of Analysis (LS-DYNA)}

Crash-testing requires a number of the test vehicle to be destroyed during the course of the tests and is also time consuming and uneconomical. One new recent trend that is gaining vast popularity is computer simulated crash-testing. Here instead of a real vehicle, a FE (Finite Element) model of the vehicle is generated and is used to carry out the different tests that were carried out before using actual vehicles.

There are several software packages that are equipped to handle the crash-testing of vehicles, but one of the most popular is from Livermore Software Technology Corporation called LS-DYNA.

With LS-DYNA, automotive companies and their suppliers can test car designs without having to tool or experimentally test a prototype, thus saving time and expense. While the package continues to 
contain more and more possibilities for the calculation of many complex, real world problems, its origins and core-competency lie in highly nonlinear transient dynamic finite element analysis (FEA) using explicit time integration. The application of LSDYNA covers a wide range of industries.

\section{Outline of this Paper}

The outline of this paper is to present the dynamic analysis of a vehicle using LS-DYNA software, also proposes some alternative materials in order to reduce impact shock and to increase the toughness of the body parts and decrease the weight. The main purpose was the reduction of the weight of the vehicle, the lower values of the results is not unexpected. The Test model 2 will experience lower forces as a result of its lower weight. Than the test model .

\section{LITERATURE REVIEW}

Simulated crash-testing is being increasingly by various institutes to study the outcome of a vehicular in various situations under different conditions. The advantage of simulation is that the FE models can be reused again and again and also the user has the freedom to change any of the parameters of the test and also the user can vary the material properties as well as the type of material of the parts in the vehicle.

The FE model was then used to simulate crash test. The FE software used here to carry out the simulation was LS-DYNA. One of the tests carried out was the Frontal-offset crash at $40 \mathrm{mph}$. Before the simulation could be carried out, several other preprocessing conditions have to be specified. The test results were verified using results from actual crash-test reports. Present runtimes on high-end workstations for LS-DYNA vehicle models are still measured in days, while multi-body run-times are typically less than $1 \mathrm{~h}$, even for the most complex models.

Thacker et.al [1] conducted crash-testing simulation study of a 1997 Honda Accord. Originally, a real vehicle was obtained and then the vehicle was stripped down to its basic parts, each component was identified, labeled, and the material evaluated. Data that could be efficiently extrapolated from existing sources were collected

A similar study was carried out by Cheng et.al [2], wherein the aim of the study was to reverse engineer a 1997 Honda Accord DX Sedan and to develop a FE model of the vehicle to be that can be successfully used in computational simulations of full frontal, offset frontal, side, and oblique car-to-car impact testing

The crashworthiness was then compared to existing physical data of a 2007 Jeep Wrangler that has been manufactured with all safety standards and technology. These comparisons were made to evaluate the crashworthiness of the pre safety standards.

\section{NHTSA Crashworthiness}

Every year the NHTSA (National Highway Traffic Safety Administration) evaluates crash safety for cars and trucks. NHTSA chooses new vehicles, which are predicted to have high sales volume or have improved safety equipment.

Tests are conducted to measure how well occupants are protected in a head-on collision. Based on the result from the test, the vehicle is given a one to five star rating, five stars being the most protective and one being the worst. The crash test ratings are only meaningful when comparing vehicles within the same weight class. Federal law requires all passenger cars to pass a $30 \mathrm{mph}$ frontal crash while the NCAP test involve crashing into a fixed barrier at $35 \mathrm{mph}$. Instruments are placed in the vehicle to record the response of the structure during the crash. Anthropomorphic dummies are placed in the driver and passenger seats for the test, they measure the force of the impact to the chest, head and leg. These readings are the basis for the five start rating. The test program deals only with crashworthiness and indicates how well a car can protect its occupants in a frontal collision

\section{Alternative Materials}

Due to the age of the vehicle, the majority of the components were constructed of mild steel. However, in light of recent developments in manufacturing processes, the use of lighter substitutes to steel in the construction of the vehicle components has been steadily increasing. One of the most widely substitutes for steel is aluminum. In considering the total life-cycle of an automobile covering four stages (pre-manufacturing, manufacturing, use, and postuse), it is apparent that during the operational stage of a vehicle, aluminum is proven to be a reliable alternative for traditional materials currently used in automotive body structures largely due to its cost effectiveness and superior performance due to light weight

In Test model 1, the materials used are the original materials that were used to manufacture the vehicle. However, in Test model 2, the materials used were updated in relation to the increased use of lighter alloy metals for manufacturing automobiles. The materials that were use in the two test models are

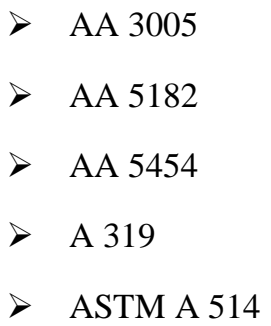


Simulation of Vehicular Frontal Crash-Test

\begin{tabular}{|l|l|l|}
\hline Material & & Test Model 2 \\
\hline \multirow{4}{*}{ Aluminium } & AA 3005 & Radiator \\
\cline { 2 - 3 } & AA 5182 & $\begin{array}{l}\text { Door, Hood, Fonder, } \\
\text { Wheel housing }\end{array}$ \\
\cline { 2 - 3 } & AA 5454 & Tire rim \\
\cline { 2 - 3 } & A 319 & Engine \\
\hline \multirow{2}{*}{ Steel } & $\begin{array}{l}\text { ASTM } \\
\text { A514 }\end{array}$ & Rail \\
\hline
\end{tabular}

Tab: Materials Used for Test model 2

\section{OVERVIEW}

Simulation a frontal impact crash-test of a vehicle model moving at a velocity of $15.65 \mathrm{~m} / \mathrm{s}$ or $35 \mathrm{mph}(\approx 56.3 \mathrm{kmph})$ in to a rigid immovable barrier is to be carried out and analyzed. It is assumed that the brakes are not applied during the crash event. The results obtained will then be validated and compared with the results of the same crash analysis performed by the NCAC (National Crash Analysis Center). The reason for comparing with the NCAC is that the institute has already conducted the same test under the same conditions by using a physical test vehicle. Then developed a finite element model of the vehicle by the process of reverse engineering. Then again carried out the same test under the same test conditions on the finite element model and validated their results by comparing with the results obtained from the physical test.

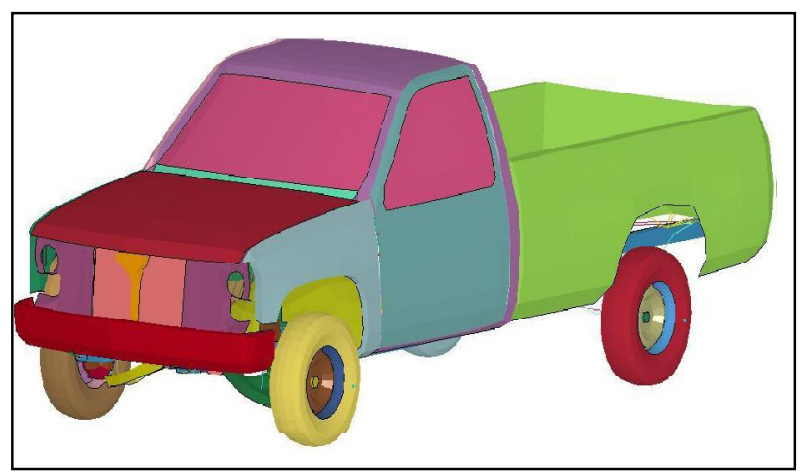

Fig: FE model of a Chevrolet C-1500

\begin{tabular}{|l|c|c|c|}
\hline & $\begin{array}{c}\text { NCAC } \\
\text { Model }\end{array}$ & $\begin{array}{c}\text { Test } \\
\text { Model1 }\end{array}$ & $\begin{array}{c}\text { Test } \\
\text { Model2 }\end{array}$ \\
\hline Weight(kg ) & 2013 & 1884 & 1654 \\
\hline $\begin{array}{l}\text { Number of } \\
\text { parts }\end{array}$ & 251 & 65 & 65 \\
\hline $\begin{array}{l}\text { Number of } \\
\text { elements }\end{array}$ & 58313 & 10729 & 10729 \\
\hline
\end{tabular}

Tab: Comparison NCAC model and Test models

\section{METHODOLOGY}

The frontal-impact crash-testing is conducted using a Chevrolet $\mathrm{C} 1500$ as the test FE model. The vehicle has an initial velocity of $35 \mathrm{mph}$ (approx. 56 $\mathrm{kmph}$ ) before it impacts the wall. The simulation is given a termination time of $0.15 \mathrm{secs}$. The reason for termination time is that for rigid barriers, deceleration rates are very high. Numerous instrumental tests carried out in the past show that most energy transfer in a head-on or frontal vehicle impact with a rigid barrier occurs within 0.2 seconds and can be as short as 0.07 to 0.02 seconds

To the generated model simulation is done in 3 steps

1. Pre processing

2. Solver

3. Post processing

The post-processor is used to read the database file from the simulation engine and displaying the results graphically.

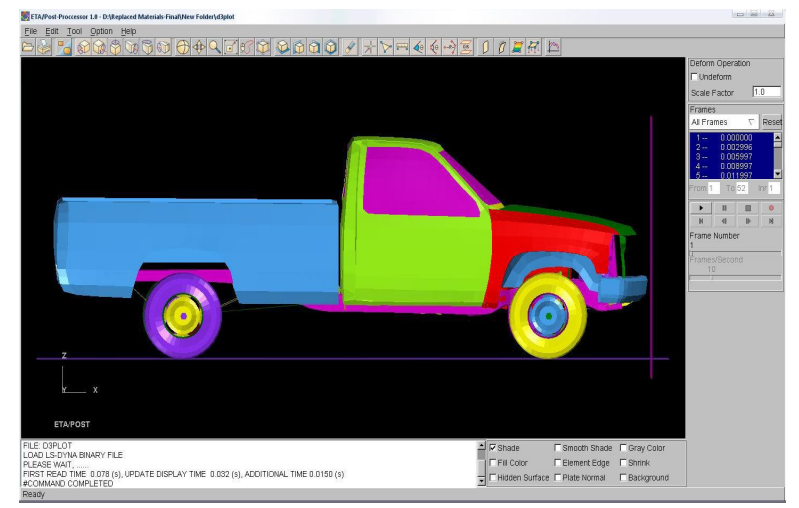

\section{Element Formulation}

The completed model contains approximately 65 parts, 61 materials and 10693 elements and 11060 nodes. Structural components and specific element types used in the model include

- Solid elements

- Belytschko - say shell element

- Hughes-Liu beam element

\section{Boundary Conditions}

The function of the boundary conditions is to create and define constraints and loads on finite element models. To simulate a full vehicle car crash, all loads and boundary conditions that occur in the actual crash event need to be modeled. Just as a car is subjected to gravitational loads in real life, the simulated model should have a representative gravity force applied. Friction forces between the tires and the road surface play an important role in how the vehicle behaves on impact, so these have to be accounted for in the simulation. The tires in real life are filled with air and will affect the severity of the impact. Modeling of the tires has to be able to simulate the interaction of the tires upon impact. A 
velocity has to be applied to the vehicle in a manner as to not impart any unrealistic acceleration or cause the simulation to run for an extended amount of time. Fortunately, Ls-Dyna provides methods to simulate all of these requirements

\section{RESULTS AND DISCUSSION}

Two simulations were carried out for the frontal impact; the Test model 1 had the same materials as the NCAC model while in the Test model 2, newer materials for the parts were employed. The results obtained were then validated with the results obtained of similar simulations performed by the NCAC.

The sequence of images shown below is the image of the vehicle before and after it impacts the rigid wall with the specified velocity of $35 \mathrm{mph}$ $(\approx 56 \mathrm{kmph})$. A collection of images showing the impact of the Test model 1 as it impacts the wall from time $\mathrm{t}=0$ to $\mathrm{t}=0.15 \mathrm{secs}$ at time intervals $0,0.05,0.10$ and $0.15 \mathrm{sec}$.

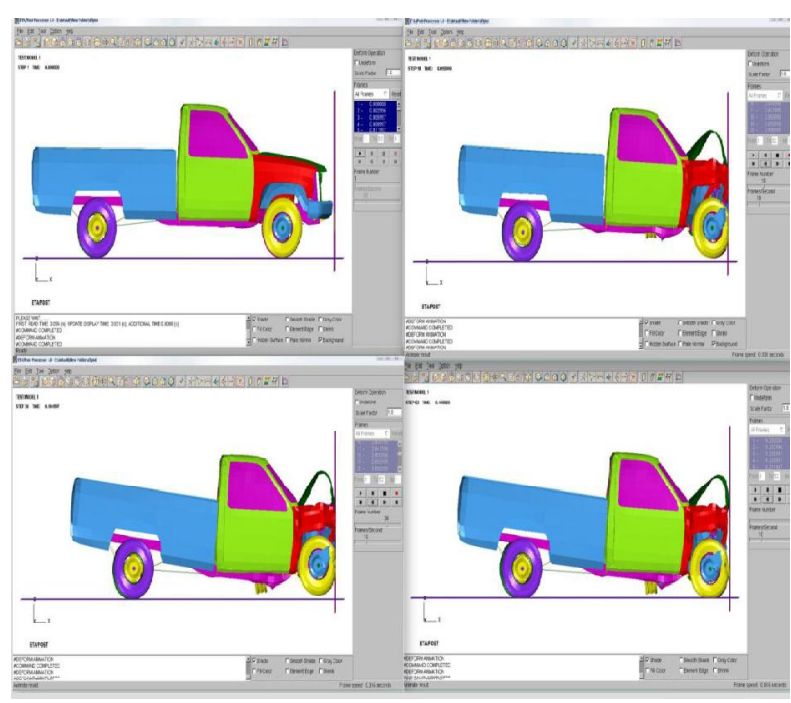

Fig Crash sequence of Test model1

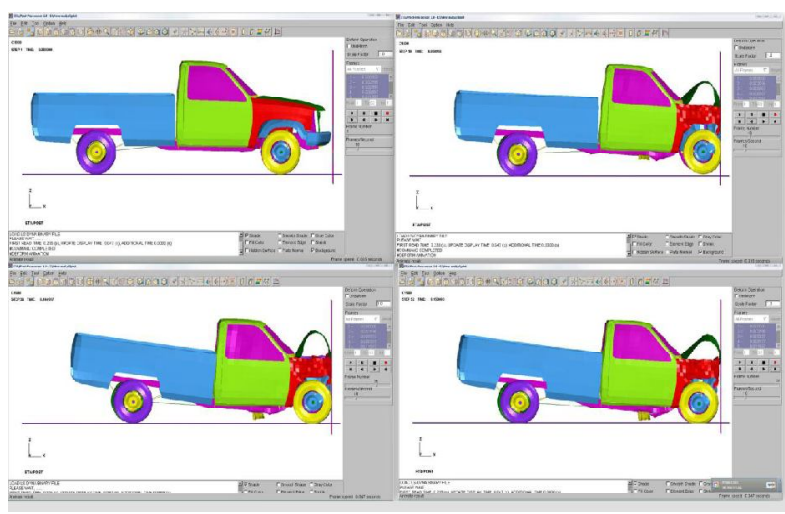

Fig Crash sequence of Test model 2

\section{Energy Balance Graphs}

First of all, the energy balance graphs between the Test model 1 and Test mode 2 are compared to comprehend the performance of Test model 2 with respect to Test model 1

Graphs showing the Kinetic energy, Internal energy and the Total energy Vs Time obtained after the simulation are displayed for both the simulations and also for the NCAC test.

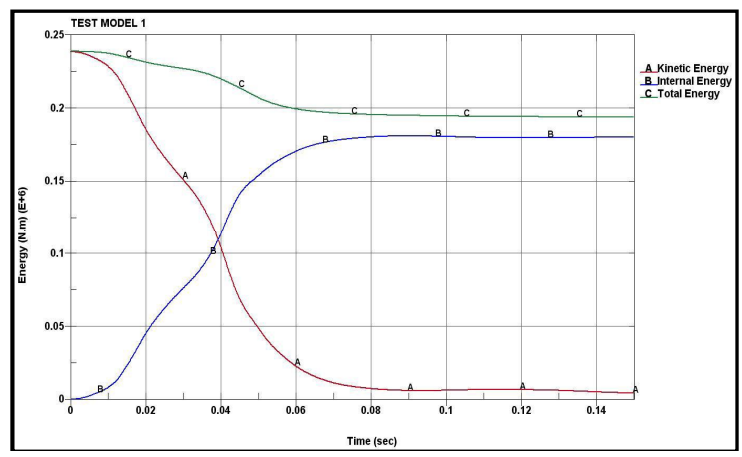

Fig: Energy balance graph of test model1

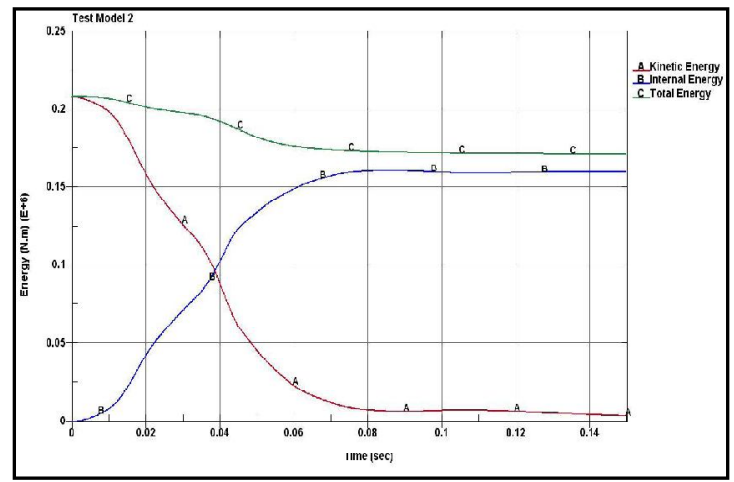

Fig: Energy balance of Test model 2.

As observed, the most of the energy of the impact is absorbed by the bumper, radiator, engine and the rails. These components absorb most of the energy of the crash before the tires impacts the wall. The maximum values of kinetic energy of the Test model 1 and Test model 2 are $239.126 \mathrm{~kJ}$ and $208.301 \mathrm{~kJ}$ respectively. For the Test model 2, whose main purpose was the reduction of the weight of the vehicle, the lower values of the results is not unexpected. The Test model 2 will experience lower forces as a result of its lower weight.

\section{Deceleration Vs Time}

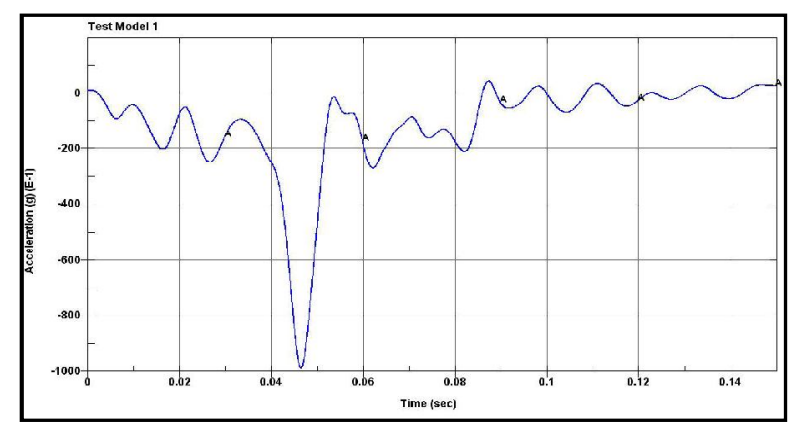

Fig: Acceleration Vs Time graph of Test Model 


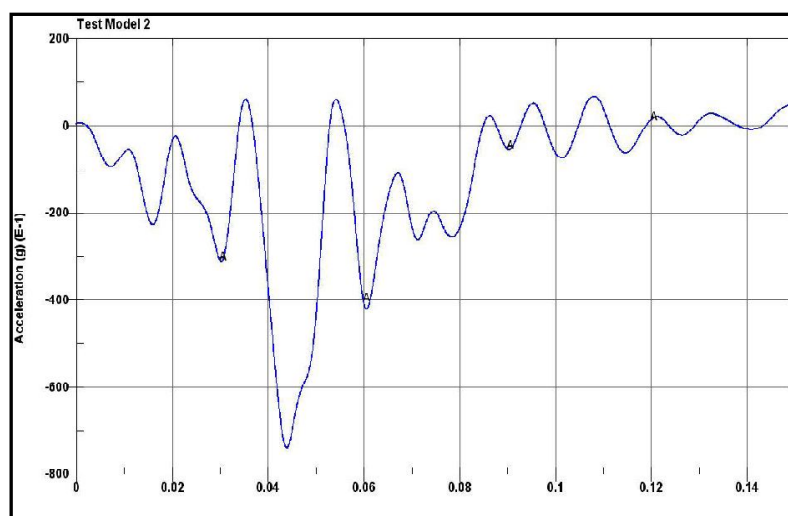

Fig: Acceleration Vs Time graph of Test Model 2

As can be seen from the graph, there is a small difference between the deceleration profile of the Test model 1 and the Test model 2 The maximum deceleration for the Test model 1 and the Test model 2 are found to be $98.94 \mathrm{~g}$ and $84.83 \mathrm{~g}$ respectively

Since the deceleration is related to the mass of the body and as is known that the Test model 2 has a lower mass than Test model 1 as given in Tab 3.1. Therefore, the lower value of the deceleration of the Test model 2 is not unexpected

\section{Velocity Vs Time}

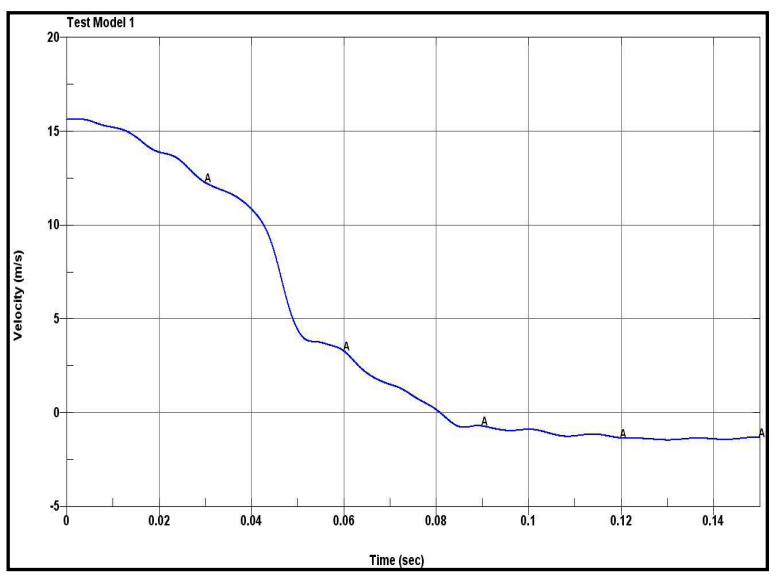

Fig: Velocity Vs Time graph of Test model 1

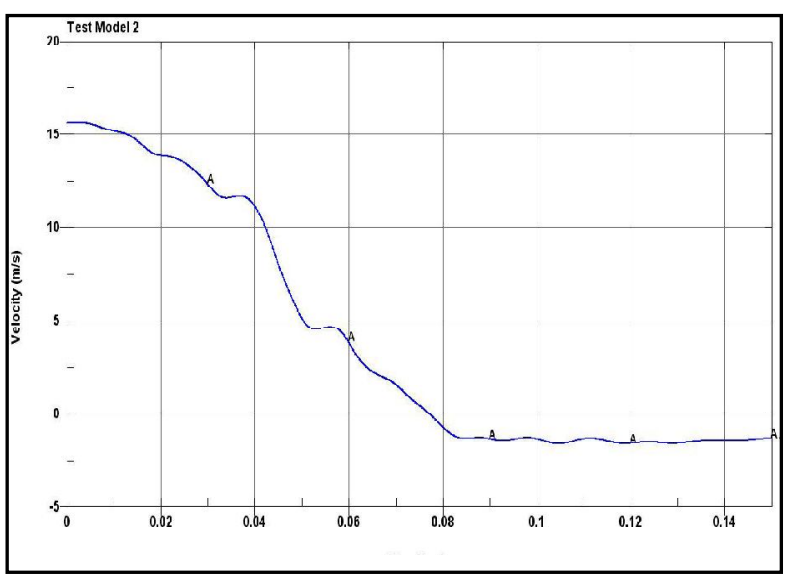

Fig: Velocity Vs Time graph of Test model 2
As can be seen from the graph, the velocity profiles of both the Test models follow very similar profiles. Here also there is the presence of a small negative velocity towards the end of the crash event. This is caused as a result of the forces generated due to the impact of the vehicle against the wall.

\section{SCOPE OF FUTURE WORK.}

The FE model can be used for further simulation of in the simulations of the offset frontal impact test, where one side of the front of the vehicle is impacted against a barrier or another vehicle. Other tests include the side impact test, where a vehicle is impacted from the side by and oncoming vehicle and oblique car-to-car impacts the two or more vehicle take part in a collision. Rollover simulation can also be carried out wherein the vehicle rolls on its sides due to the cause of an impact or other factors

Further crash-testing involving the effects of the crash forces on the occupants of the vehicle can also be carried by using FE models of test dummies. Human-surrogate dummies called Anthropomorphic Test Devices (ATDs) could be placed inside the FE vehicle models and an entire crash test event could be simulated. The FE dummies are used to simulate the behavior of a vehicle occupant in the event of a crash. These FE dummies can then be placed inside the vehicle and the crash-simulation performed, they can provide various insights into the dynamic behavior of the human body in the event of a crash. This, however, requires detailed occupant compartment geometry as well as a detailed dummy model. This could easily double the FE models complexity and greatly increase the needed computer resources

\section{CONCLUSIONS}

The overall objective of the work was to simulate a Frontal crash-test and validate the results of the simulations obtained from the crash-test. Simulation was performed using the LS-DYNA software package.

1. The results of the simulations were validated by comparing with the results of the NCAC model simulation.

2. As was observed, the bumper, engine and the rails absorb most of the energy before the wheel impacts the wall. Almost half of the energy of the crash is absorbed by these components after about $0.04 \mathrm{sec}$ of the crash initiation.

3. It has been observed that there is minimum deformation of the cabin and also there was minimum intrusion of the components into the cabin. Therefore, it can be assumed that the occupants in the cabin would not be caused any injury by a component intruding into the cabin in the event of the crash.

4. Due to the limited availability of computer resources, a simpler model of the test vehicle was 
chosen, which ultimately caused the inaccuracies of the results. As the number of elements of the test models is lower than that of the NCAC model, therefore, there are certain inaccuracies in the results.

5. For more accurate results a more accurate model would be required but the computer resources required for the simulations would have been much higher. Therefore a compromise had to be found wherein the simulation could be performed without the result deviating too much.

6. The graphical results obtained all showed that the test models $\square$ behavior were similar to that of the NCAC model throughout the crash event.

7. The slightly different behavior of the Test model 2 can be attributed to the fact the material of the components were changed which had change the some of the outcome of the simulation.

\section{REFERENCES}

[1] J.G. Thacker, S.W. Reagan, J.A. Pellettiere, et.al, "Experiences during development of a dynamic crash response automobile model", Journal of Finite Element Analysis and Design 30 (1998) 279-295.

[2] Z.Q. Chenga, J.G. Thackera, W.D. Pilkeya, W.T. Hollowellb, et.al, "Experiences in reverse-engineering of a finite element automobile crash model", Journal of Finite Elements in Analysis and Design 37 (2001) 843-860.
[3] Abdullatif K. Zaouk, Nabih E. Bedewi, Cing-Dao Kan, et.al, "Validation of a non-linear finite element vehicle model using multiple impact data", The George Washington University FHWA/NHTSA National Crash Analysis Center.

[4] M.A. Virginia, "Crashworthiness of a Pre-NCAP Safety Standard Light Truck and Corresponding Suspension Analysis", Wichita State University (2001).

[5] Gary R. Consolazio, Jae H. Chung, Kurtis R. Gurley, "Impact simulation and full scale crash testing of a low profile concrete work zone barrier", Journal of Computers and Structures 81 (2003) 1359-1374.

[6] S. W. Kirkpatrick, "Development and Validation of High Fidelity Vehicle Crash Simulation Models", SAE Publications, Presented at the 2000 International Congress and Exposition (2000) SAE Paper No. 00PC-248.

[7] Geoff Davis, "Materials for Automobile Bodies", Elsevier, U. K. (2003) 10-60.

[8] J.O. Hallquist, "LS-DYNA Keyword User $\square$ s Manual", Livermore Software Technology Corporation (1997).

[9] Zhipeng Zeng, Yanshu Zhang,Yi Zhouc, et.al, "Superplastic Forming of Aluminum Alloy Car Body Panels", Materials Science Forum 475-479 (2005) 3025-3028.

[10] U.N. Gandhi and S. J. Hu, "Data-Based Approach in Modeling Automobile Crash", Jouranal of Impact Engineering 16 (1995) 95-118.

[11] A. Deba, M.S. Mahendrakumara, C. Chavan, J. Karve, D. Blankenburg, S. Storenb, "Design of an Aluminium-Based Vehicle Platform For Front Impact Safety”, Journal of Impact Engineering 30 (2004) 1055-1079. 